\section{Clinical candidates of small molecule p38 MAPK inhibitors for inflammatory diseases}

\author{
Li Xing \\ Biotherapeutics Chemistry, Pfizer \\ Worldwide Research and Development, \\ Cambridge, MA, USA
}

\section{Abstract}

The trigger and etiology of chronic inflammatory diseases are not well understood, hindering the development of efficient therapeutic approaches. The observation that abnormal activity of the p38 MAPK is common to all inflammatory diseases raised the expectation that p38 inhibitors would serve as general anti-inflammatory therapeutics. A large number of inhibitors were consequently discovered. Several compounds of different scaffolds, blocking the p38 MAPK signaling pathway, have entered phase II clinical trials for rheumatoid arthritis, chronic obstructive pulmonary disease, pain, cardiovascular diseases, and cancer. As I review here, in almost all cases the clinical trials have failed, leading to re-design of compounds and re-evaluation of p38 as a suitable target. I describe how structural features, unique to $\mathrm{p} 38 \alpha$, have been employed in the inhibitor design and achieved high degree of kinome selectivity. I then focus on some of the drugs that reached human trials and summarize their in vitro/in vivo pharmacological profiles and the related outcomes from clinical investigations. These compounds include VX-745, VX-702, R0-4402257, SCIO469, BIRB-796, SD-0006, PH-797804, AMG-548, LY2228820, SB-681323 and GW-856553. Finally, I discuss novel suggested approaches for the use of p38 inhibitors such as combining p38 inhibition with inhibiting other targets that function in parallel inflammatory pathways for achieving efficacy in treating inflammatory diseases.

\section{Compounds}

VX-745, VX-702, R0-4402257, SCI0-469, BIRB-796, SD-0006, PH-797804, AMG-548, SB681323, LY2228820, GW-856553.

\section{Inflammatory diseases}

Inflammation and immunity forms the bases of many physiological and pathological processes. Though a beneficial host response during an infection, inflammation can contribute substantially to the pathogenesis of many chronic diseases. In an exaggerated immune response, the immune system mistakenly attacks the self, targeting the body's own cells, tissues, and organs.1,2 Rheumatoid arthritis, inflammatory bowel disease, psoriasis, lupus and multiple sclerosis are all autoimmune diseases, conditions in which the immune system loses its ability to differentiate the self from the foreign and directs an attack against healthy cells and tissues. ${ }^{3}$ Systemic inflammation is also involved in the pathogenesis of chronic obstructive pulmonary disease (COPD).4-6 Reduced lung function is associated with increased levels of systemic inflammatory markers, which may have important pathophysiological and therapeutic implications for subjects with stable COPD.

\section{Biological treatments}

Treatment with infliximab, adalimumab, etancercept, anakinra, and tocilizumab reduces joint pain and swelling, and retards progression of bone loss in patients whose disease is unsatisfactorily controlled by conventional disease-modifying anti-rheumatic drugs. 7,8 They act by antagonizing pro-inflammatory mediators such as TNF- $\alpha$, IL-6, IL-1 and IL-1 receptor. ${ }^{9-12}$ However, these biologic agents are limited due to the requirement for parenteral administration, difficulty in dose titration, poor reversibility, induction of host neutralizing antibody response, high production costs, and a significant population of patients refractory to the treatment.

\section{p38 MAPK}

Excessive production of TNF- $\alpha$ and other pro-inflammatory cytokines is involved in the pathogenesis of rheumatoid arthritis, Crohn's disease, inflammatory bowel disease, and psoriasis.13,14 In the innate immune response mitogen-activated protein kinase (MAPK) and nuclear factor- $\kappa \mathrm{B}(\mathrm{NF}-\kappa \mathrm{B})$ are activated by pattern recognition receptors (PRRs) upon binding of the pathogen-associated molecular patterns (PAMPs). The fourteen MAPKs discovered in mammalian cells are crucial to generating immune responses. Amongst them extracellular signal-regulated kinase (ERK), p38 and Jun N-terminal kinase (JNK) have been extensively studied in the context of innate immunity. ${ }^{15-18}$ Altogether they play pivotal roles in the MAPK signal transduction pathway that cells use to adapt to inflammatory and stressful conditions. Pathogens or inflammatory stimuli initiate a phosphorylation cascade mediated by p38 kinase that leads to the transcription and translation of inflammatory response-associated genes that encode proteins such as TNF- $\alpha$, IL-1 $\beta$, IL-6, and IL-8.16,19
Correspondence: Li Xing, Biotherapeutics Chemistry, Pfizer Worldwide Research and Development, 610 Main Street, Cambridge, MA 02139, USA.

Tel.: 617.674.7462.

E-mail: li.xing@pfizer.com

Key words: p38 MAP kinase; clinincal candidates.

Acknowledgements: we acknowledge the work of colleagues on the p38 program teams over many years on the discovery and development of Pfizer p38 inhibitor clinical candidates. Compound PH797804 is commercially available via Sigma Aldrich (catalog \# PZ0259).

Conflict of interest: the author declares no conflict of interest.

Received for publication: 31 August 2015. Revision received: 27 November 2015.

Accepted for publication: 27 November 2015.

This work is licensed under a Creative Commons Attribution NonCommercial 3.0 License (CC BYNC 3.0).

(C) Copyright L. Xing, 2015

Licensee PAGEPress, Italy

MAP Kinase 2015; 4:5508

doi:10.4081/mk.2015.5508

TNF- $\alpha$, IL-1 $\beta$, and IL- 6 are macrophage- and fibroblast-derived proteins that induce expression of inflammatory mediators such as COX-2, inducible nitric-oxide synthase, adhesion molecules, and metalloproteinases, resulting in synovial inflammation and associated cartilage and bone destruction. The expression of cytokines and chemokines during an innate immune response could lead to subsequent induction of the adaptive immune response further intensifying the amplitude and duration of an inflammatory reaction. Inhibition of p38 MAPK blocks this cytokine production and the amplification of the inflammatory cascade. Modulation of p38 by ATP-competitive small molecules has led to the generation of a variety of novel p38 inhibitors as potential therapeutics for the treatment of inflammatory conditions including Crohn's disease, COPD, psoriasis, and rheumatoid arthritis (RA). ${ }^{19-23}$

The p38 MAP kinase family consists of four isoforms: $\alpha, \beta, \gamma$, and $\delta$. These kinases show a high degree of sequence homology, with 60 to $75 \%$ overall sequence identity and $>90 \%$ within the kinase domain. ${ }^{24}$ The $\mathrm{p} 38 \beta$ kinase is the closest structural homolog to $\mathrm{p} 38 \alpha$, sharing $75 \%$ overall sequence identity, and even higher in the ATP binding site (close to 90\%). In general p38 $\alpha$ and $\beta$ kinase inhibition parallels with each other. The $\alpha$ and $\beta$ isoforms are ubiquitously expressed, with the $\alpha$ isoform 
being the better characterized in terms of its role in inflammation.

Activation of the p38 MAPK signaling pathway also leads to the production of anti-inflammatory cytokines such as IL-10, activation of negative feedback loops initiated by the phosphorylation of transforming growth factor $\beta$ activated kinase-1-binding protein as well as up-regulation of MAP kinase phosphatases that dephosphorylate and inactivate p38 kinase, ERK, and JNK. ${ }^{25-27}$ These multiple positive and negative pathway components highlight the complex feedback mechanisms that could limit MAPK activation to prevent excessive inflammation. 18

\section{Small molecule p38 MAPK inhibitors - clinical candidates}

The p38 mitogen-activated protein (MAP) kinase is a widely prosecuted therapeutic target that has resulted in the discovery of a variety of inhibitor classes with diverse molecular architectures (Figure 1). ${ }^{20,22}$

The pyrimido-pyridazinone (VX-745) and pyridinyl-urea (VX-702) based inhibitors are first discovered by Vertex Pharmaceuticals. ${ }^{28,29}$ In human whole blood, a cellular system that mimics the physiological in vivo milieu, lipopolysaccharide (LPS)-stimulated TNF- $\alpha$ and IL-1 $\beta$ production were measured. VX-745 inhibits p38 $\alpha$ and LPS-TNF- $\alpha$ in human whole blood (hWB) at $\mathrm{IC}_{50}$ 's of $5.0 \mathrm{nM}$ and $700 \mathrm{nM}$ respectively. In RA patients it was well tolerated and produced significantly higher ACR20 response rate than placebo ( $43 \%$ vs $8 \%$ ). However, further trials were suspended after neurological effects were observed in dogs. ${ }^{30}$ With much lower penetration of the bloodbrain barrier VX-702 was chosen as a backup to VX-745. ${ }^{31}$ Two clinical trials were completed in the third quarter of 2007, one with VX-702 as a single agent in RA patients, and the other Phase II study as a QD medicine in combination with methotrexate for three months. ${ }^{32}$ In both studies, the ACR20 response rates among patients did not reach statistical significance. Reductions in the levels of C-reactive protein were observed as early as week 1 but the levels rapidly returned to baseline values by week 4 .

SCI0-469 (Talmapimod) was advanced to phase II human clinical trials for the treatment of rheumatoid arthritis, myelodysplastic syndrome (MDS), and acute dental pain. ${ }^{33-37}$ It is a selective p38 $\alpha$ inhibitor with $>1000$-fold selectivity versus ERK2, JNK1, and LCK. It potently inhibits p $38 \alpha$ at enzyme level $\left(\mathrm{IC}_{50}=9\right.$ $\mathrm{nM}$ ) and moderately inhibits LPS-induced TNF- $\alpha$ production in human whole blood $\left(\mathrm{IC}_{50}=300 \mathrm{nM}\right) .{ }^{38,39}$ Oral SCIO-469 administered at doses ranging from $90-300 \mathrm{mg}$ daily was tolerated with common adverse events in patients. In MDS patients bone marrow and cytogenetic responses were rare, suggesting low likelihood of SCIO-469 at the tested dose levels having any disease-altering activity. ${ }^{36}$ In RA patients no significant differences in ACR20 responses were found between SCIO469 and placebo. Declines in C-reactive protein and erythrocyte sedimentation rate during early treatment did not persist and were not a consequence of decreased SCIO-469 plasma levels.

BIRB796 binds at a site that is used by the purine moiety of ATP and extends into a selectivity pocket, which is not used by ATP. It displaces the Asp168-Phe169-Gly170 motif at the start of the activation loop, promoting a $D F G$ out conformation. ${ }^{40}$ Some other inhibitors bind only in the purine site, with p38 $\alpha$ remaining in a DFG-in conformation. An inhibition in solution assay (ISA) measured $\mathrm{K}_{d}$ for the non-activated $\mathrm{p} 38 \alpha$ to be $<0.8 \mathrm{nM}$. ${ }^{41}$ Selectivity pocket compounds associate with p38 $\alpha$ over 30 -fold more slowly than purine site compounds $\left(\mathrm{k}_{0 \mathrm{n}}=0.85 \times 105 \mathrm{~s}^{-1} \mathrm{M}^{-1}, \mathrm{k}_{0 \mathrm{ff}}=8.3 \times 10-6 \mathrm{~s}^{-1}\right)$, apparently due to low abundance of the DFGout conformation. At concentrations that inhibit cellular production of an inflammatory cytokine, TNF- $\alpha$, selectivity pocket compounds decrease levels of phosphorylated p38 $\alpha$ and $\beta$. In the in vitro and in vivo experiments BIRB796 inhibits all p38 MAPK isoforms. ${ }^{42}$ By binding to a different conformation of the enzyme, compounds that prevent activation offer an alternative approach to modulation of $\mathrm{p} 38 \alpha$.

Out of a series of diaryl pyrazole-based inhibitors SD-0006 was identified as a potent and selective for $\mathrm{p} 38 \alpha$ and $\beta$ MAP kinases over fifty other kinases screened including $\mathrm{p} 38 \gamma$ and $\mathrm{p} 38 \delta .43,44$ In the mouse collagen-induced arthritis (mCIA) model equivalent efficacy was shown to anti-TNF antibody treatment. 45 SD0006 demonstrated good oral anti-inflammatory efficacy and cross-species correlation between the rat, cynomolgus monkey and human. Its development has been discontinued after phase I study in human healthy volunteers.

R0-4402257 (Pamapimod) is a selective inhibitor of the $\alpha$-isoform of p38. It inhibited
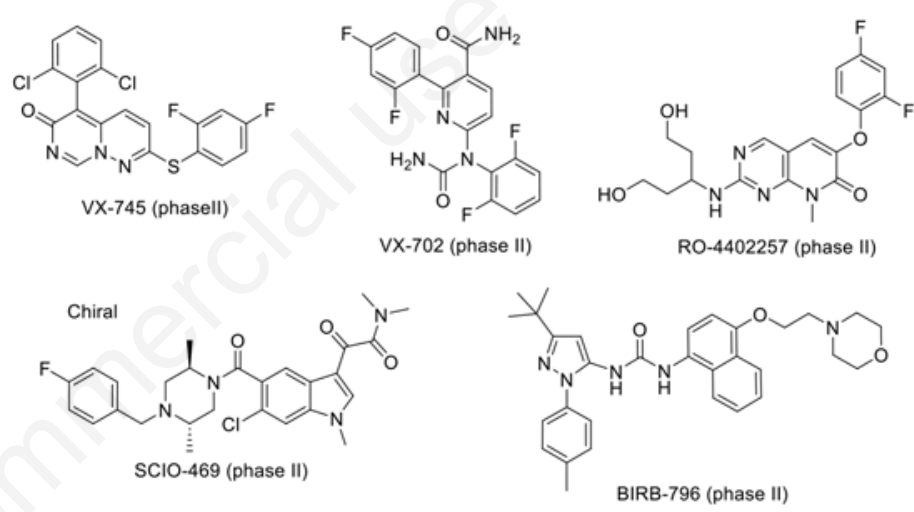

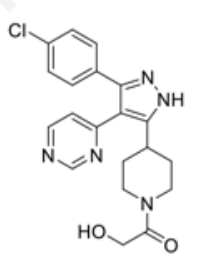

SD-0006 (phase I)

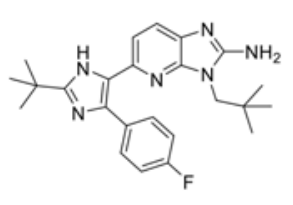

LY2228820 (phase II)
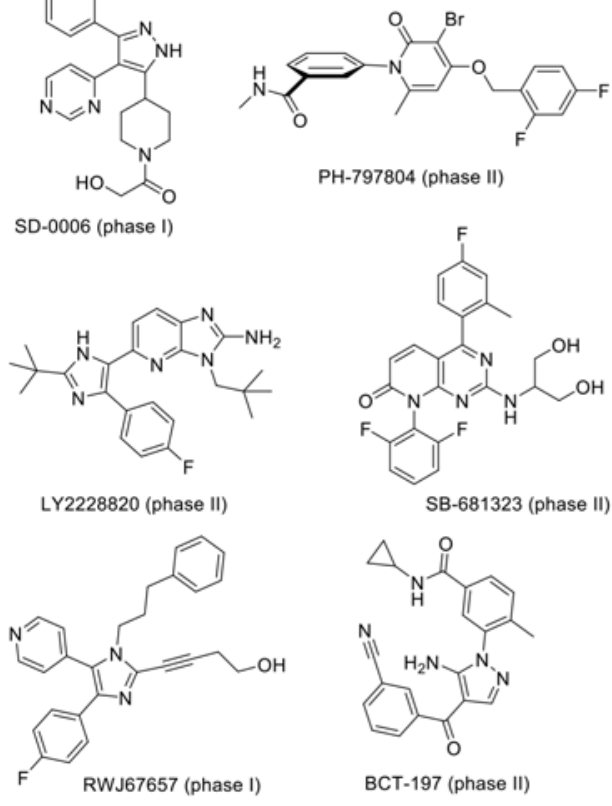

PH-797804 (phase II)

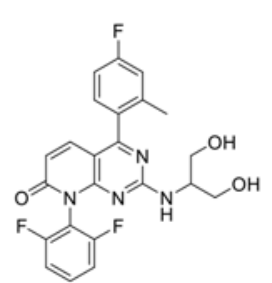

SB-681323 (phase II)

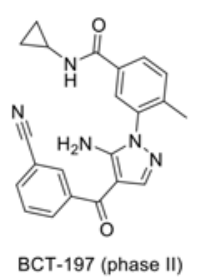

Figure 1. Clinical candidates of p38 MAPK inhibitors.

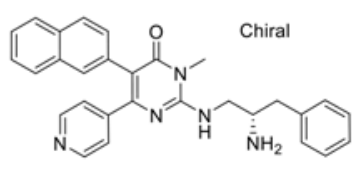

AMG-548 (phase I)

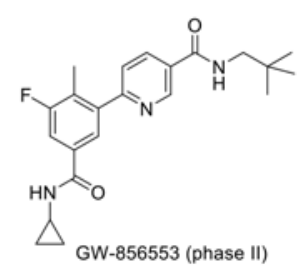

GW-856553 (phase II) 
p38 $\alpha$ and p38 $\beta$ enzymatic activity, with $\mathrm{IC}_{50}$ values of 14 and $0.48 \mathrm{nM}$ respectively, but showed no activity against $\mathrm{p} 38 \delta$ or $\mathrm{p} 38 \gamma$ isoforms. ${ }^{46}$ In murine collagen-induced arthritis, R0-4402257 reduced clinical signs of inflammation and bone loss at $50 \mathrm{mg} / \mathrm{kg}$ or greater. In a clinical study in patients with active RA R04402257 was administrated as monotherapy with comparison to methotrexate (MTX). ${ }^{47}$ After 12 week of daily therapy at one of the three doses $(50,150$ or $300 \mathrm{mg})$ no clear evidence of efficacy was demonstrated. Intriguingly, the level of C-reactive protein (CRP) initially declined in the 300 -mg patient group, but rapidly returned to baseline at the second week and remained over the rest of the study period. Typical adverse findings are liver enzyme elevation and/or skin rash. ${ }^{47,48}$

In a single dose study in COPD patients SB681323 (Dilmapimod) was shown to inhibit the p38 MAPK pathway via biomarker pHSP27 measurement and the TNF- $\alpha$ production. ${ }^{49}$ To evaluate its effect on neuropathic pain symptoms and signs 43 patients received twice-daily doses for two weeks. The average daily pain score was reduced with statistical significance compared to placebo. 50

GW-856553 (Losmapimod) is a potent p38 MAPK inhibitor of both $\alpha-\left(\mathrm{K}_{\mathrm{i}}: 8.1 \mathrm{nM}\right)$ and $\beta$ $\left(\mathrm{K}_{\mathrm{i}}: 7.6 \mathrm{nM}\right)$ isoforms. ${ }^{51} \mathrm{~A}$ post hoc analysis based on a 6 month clinical study demonstrated reduction of exacerbations with the $15 \mathrm{mg}$ twice daily dose in the subgroup of COPD patients with blood eosinophils $2 \%$ at baseline. 52 To fully support further clinical development the findings need to be explored in a prospectively designed study in a COPD population. Identification of a subgroup of patients more likely to respond to treatment is a step towards personalized medicine by offering effective therapy to specific populations of high unmet need. GW-856553 was also evaluated in patients with chronic neuropathic pain but the analgesic efficacy was not clinically meaningful. ${ }^{53}$ Additionally GW-856553 suppressed inflammation in patients with cardiovascular disease and improved vascular function. $54-56$

BCT-197 (Acumapimod) is being developed by Novartis as an oral agent for COPD. From patent application the compound inhibits $\mathrm{p} 38 \alpha$ with an $\mathrm{IC}_{50}$ value of less than $1 \mu \mathrm{M} .{ }^{57,58}$ In COPD patients BCT-197 was evaluated at single dose of 20 and $75 \mathrm{mg}$ with and/or without prednisone. The ongoing development is expected for regulatory filings in 2018. No further clinical trials in COPD patients have yet been disclosed. A Phase II study was also performed in acute renal patients undergoing cardiac surgery but development for that indication appears to have been terminated.

Using $\mathrm{p} 38 \alpha$ immune-precipitated from LPSactivated human monocytes the $\mathrm{IC}_{50}$ of RWJ67657 was measured at $30 \mathrm{nM} .{ }^{59}$ The com- pound inhibited the production of TNF- $\alpha$ and IL-1 $\beta$ by LPS-stimulated human PBMCs, with $\mathrm{IC}_{50}$ values of 3 and $11 \mathrm{nM}$, respectively. In the single-dose first-in-human (FIH) study the terminal half-life of RWJ67657 was determined to be in the range of 5.1 to $7.7 \mathrm{~h} .60$ The apparent clearance was does proportional and decreased with increasing doses. The inhibition of TNFa, IL-6 and IL- 8 were reported in a dose dependent manner. ${ }^{61}$ At the maximum dose of $1400 \mathrm{mg}$ reduction in peak serum levels of the proinflammatory cytokines exceeded $90 \%$. Furthermore RWJ67657 demonstrated potential in treating endocrine resistant breast cancer. ${ }^{62}$ Utilizing well-established xenograft tumor models RWJ67657 exhibited potent antitumor properties, markedly decreasing tamoxifen resistant tumor growth.

Follow-on to SD-0006 the lead generation and optimization efforts led to the identification of a novel pharmacophore PH-797804 as a clinical candidate for RA and COPD. ${ }^{63-66}$ First identified by molecular modeling and subsequently confirmed by chiral chromatography, PH-797804 is the more potent atropisomer (aS) of a racemic pair. ${ }^{3}$ In biochemical assays and as well as assays PH-797804 demonstrated high potency cellular $\left(\mathrm{K}_{\mathrm{i}}=5.8 \mathrm{nM}\right)$ and superior selectivity across broad human kinase genome. In human clinical trials PH-797804 was generally safe and well tolerated. These observations are on the basis of five Phase I studies, as well as three proof-of-concept studies in rheumatoid arthritis, post-herpetic neuralgia and COPD. Efficacy was demonstrated in RA patients but was not sustained after two weeks. The decline of CRP levels was also transient during the initial weeks of oral administration. Several phase II studies in moderate to severe COPD patients produced significant improvement in trough FEV1 and in dyspnea. $67-69$

In addition to treating autoimmune and the

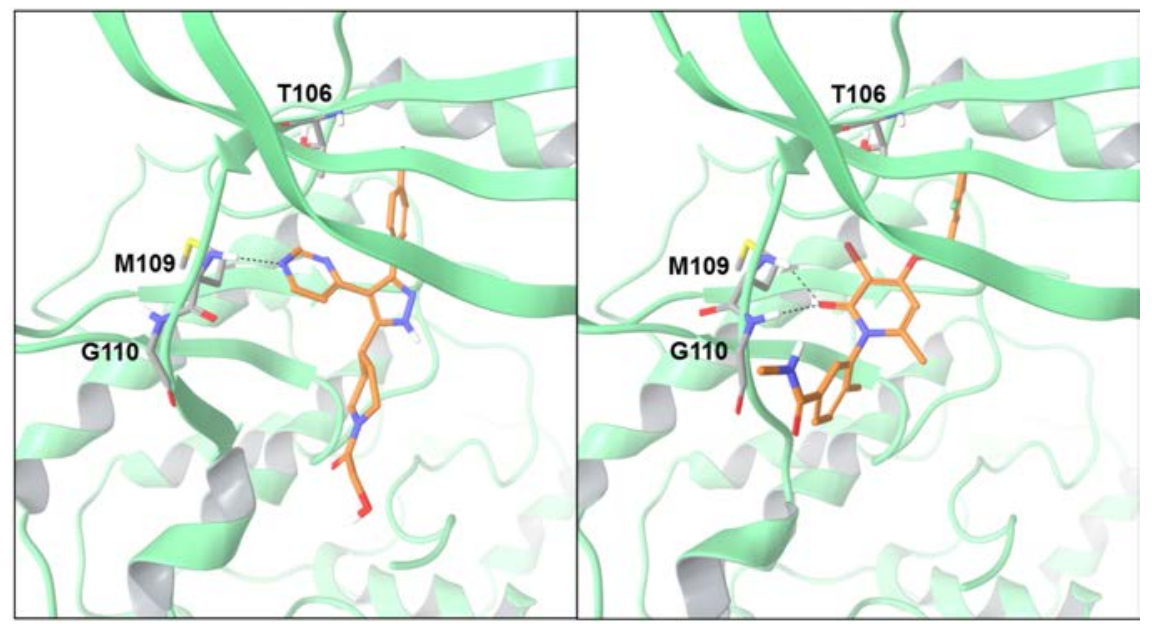

Figure 2. Binding interactions of SD-0006 and PH-797804 illustrated by X-ray crystal structures [PDB code: A) $3 \mathrm{HL7}$ and B) 3HLL, respectively]. related disorders LY2228820 dimesylate (Ralimetinib) is being investigated in a clinical trial in patients with ovarian cancer. The compound potently inhibited $\mathrm{p} 38 \alpha$ - and $\beta$-isoforms in vitro ( $\mathrm{IC}_{50}$ : 5.3 and $3.2 \mathrm{nM}$ respectively) and produced significant tumor growth delay in multiple animal cancer models. ${ }^{70}$ Several additional p38 MAPK inhibitors were evaluated clinically for the treatment of chronic inflammatory disorders. These included BMS-582949, ARRY-797 and AMG-548.71-73 Either their structures were not disclosed and/or there was very little clinical data reported.

\section{Structural biology of p38 $\alpha$}

Structural information of $\mathrm{p} 38 \alpha$ kinase is rich with more than a hundred published structures generated by X-ray crystallography over the past decades. Besides a few apo, unphosphorylated protein forms, most of the three-dimensional structures are binary complexes of p38 $\alpha$ kinase and small molecule inhibitors that compete for binding with cellular ATP. ${ }^{43,74-81}$ The kinase hinge recognition predominantly involves a hydrogen bond with the Met109 backbone NH group. Some inhibitors engage an additional hydrogen bond with the upstream residue His107 via its backbone carbonyl, strictly resembling the donoracceptor pattern of the nucleoside interaction of ATP. 82

\section{DFG-out binding capacity}

In addition to the catalytically active conformations, the DFG-out arrangement constitutes one of the frequently encountered inactive kinase conformations. ${ }^{83,84}$ When the specific classes of inhibitor molecules bind, the conserved Asp-Phe-Gly (DFG) motif at the beginning of the activation loop rotates out of the 
ATP site, creating a new pocket that is inaccessible in the active kinase conformation. By exploiting the induced pocket, submicromolar p38a kinase inhibitors were achieved sparing the conventional hinge interaction entirely. ${ }^{82}$ BIRB796 exploits this catalytically incompetent conformation of the p38 kinase, which was envisioned to afford its high degree of selectivity against other protein kinases. 40

\section{Met109-Gly110 peptide bond flip}

Binding interactions of PH-797804 was differentiated from the SD-0006 compound series as depicted by Figure 2. The pyrazole group of SD-0006 serves as a central framework that helps to optimally position the two aromatic groups in the ATP binding site of p38a kinase. Crystal structure represented by SD-0006 has revealed a number of binding elements. One edge of the pyrazole moiety is stabilized by interactions with the flexible glycine flap that contains the consensus GXGXXG motif. One of the nitrogen atoms of the pyrazole ring directly interacts with the carboxylate side chain of Asp168. The 4-pyrimidine overlaps with adenine of ATP binding and forms conserved hydrogen bond with the hinge of $\mathrm{p} 38 \alpha$ via Met109. The 4-chlorophenyl group binds in the lipophilic pocket of $\mathrm{p} 38 \alpha$. Overall, the binding of SD-0006 did not in any significant way perturb the native conformation of the apo p $38 \alpha$ structure. $44,63,74,75$

In comparison with the earlier biaryl pyrazole based structure, PH-797804 not only retained the conserved elements of binding to p38 $\alpha$ kinase in the conventional kinase inhibition mode but also demonstrated unique structural features. ${ }^{63} \mathrm{~A}$ dual hydrogen bond to the backbones of Met109 and Gly110 was observed which requires a peptide bond flip of Gly110. The 2,4-difluorophenyl group of PH-797804 is encapsulated in a lipophilic pocket of $p 38 \alpha$ kinase, completely shielded from the solvent. The contour of the pocket appears to be thoroughly complementary to the halogenated phenyl ring of the inhibitor, from which a major portion of the binding free energy is derived as suggested by modeling studies. This hydrophobic pocket, unoccupied by ATP, appears to be the anchor point for the positioning and orientation of $\mathrm{p} 38 \alpha$ kinase inhibitors of diverse chemical scaffolds. The gatekeeper residue Thr106, sitting at the entrance thus controlling the access to the pocket, therefore is of essential importance to the binding affinity of p38 $\alpha$ inhibitors.

\section{$\mathrm{PH}-797904$ is the potent atropisomer}

Represented by PH-797804 the novel series of highly potent and selective p38 mitogenactivated protein (MAP) kinase inhibitors was developed originating from a substituted $N$ - aryl-6-pyridinone scaffold. Due to steric constraints imposed by the pyridinone carbonyl and the $6,6^{\prime}$-methyl substituents, the rotation around the connecting bond of the pyridinone and the N-phenyl ring is restricted. This gives rise to discrete conformational isomers that do not inter-convert under ambient conditions. Molecular modeling predicted that the two isomers should differ in their binding affinity to p38 $\alpha$ kinase, whereas the atropic $S$ isomer $(\mathrm{a} S$ ) binds favorably, the opposite $\mathrm{a} R$ isomer incurs significant steric interferences with the p38 $\alpha$ kinase. Chiral chromatography and small molecule X-ray diffraction confirmed the more potent a $S$ atropisomer (PH-797804) of the racemic pair with an $\mathrm{IC}_{50}$ of $16 \mathrm{nM}$ in the $\mathrm{p} 38 \alpha$ enzyme assay, whereas the off-isomer $\mathrm{PH}$ 797805 is more than 100 -fold less potent $\left(\mathrm{IC}_{50}\right.$ : $1800 \mathrm{nM}$ ). MAP kinase modulated cytokine production (LPS-stimulated TNF- $\alpha$ and IL-1 $\beta$ ) in whole blood were inhibited with comparable 26 -fold differences in $\mathrm{IC}_{50}$ values by $\mathrm{PH}-797804$ (85 nM) and PH-797805 (4600 nM).

\section{TXXXG motif imparts kinome selectivity}

The pyridinone class of compounds exhibits exceptional selectivity for p38 MAP kinase versus other kinases due to a unique binding mode involving a dual H-bond motif, engaging the backbones of Met109 and Gly110 residues, with a flipped peptide conformation of Gly110 from the conventional state. The backbone flip occurs in $p 38 \alpha$ due to the presence of the glycine in the hinge region, which has no side chain and consequently has sufficient conformational flexibility to induce a peptide flip (Figure 3). Combined with the gatekeeper Thr106 the TXXXG sequence motif underscores the potency and selectivity superiority of PH-797804. Based on bioinformatics analysis the TXXXG motif is only conserved in a few kinases in the human kinome. ${ }^{33}$ Specifically, $\mathrm{p} 38 \alpha, \mathrm{p} 38 \beta$ and Myt-1 are the only protein kinases that contain the corresponding glycine and a threonine at the gatekeeper position. These findings formed the bases of the structural rationale and theoretical prediction of the high level of selectivity. Myt-1 is a mixed serine/threonine and tyrosine kinase upstream of CDKs. Its kinase domain is merely $23 \%$ identical to $\mathrm{p} 38 \alpha$ in primary structure thus cross-reactivity is not anticipated. This was confirmed by a marginal Myt-1 inhibition of $14 \%$ at 10 M concentration of PH-797804. Over a hundred kinases have been screened, and $\mathrm{PH}$ 797804 was found completely selective with no off-target signal at the highest concentration of $10 \mu \mathrm{M}$. In cellular assays PH-797804 demonstrated superior potency and selectivity consistent

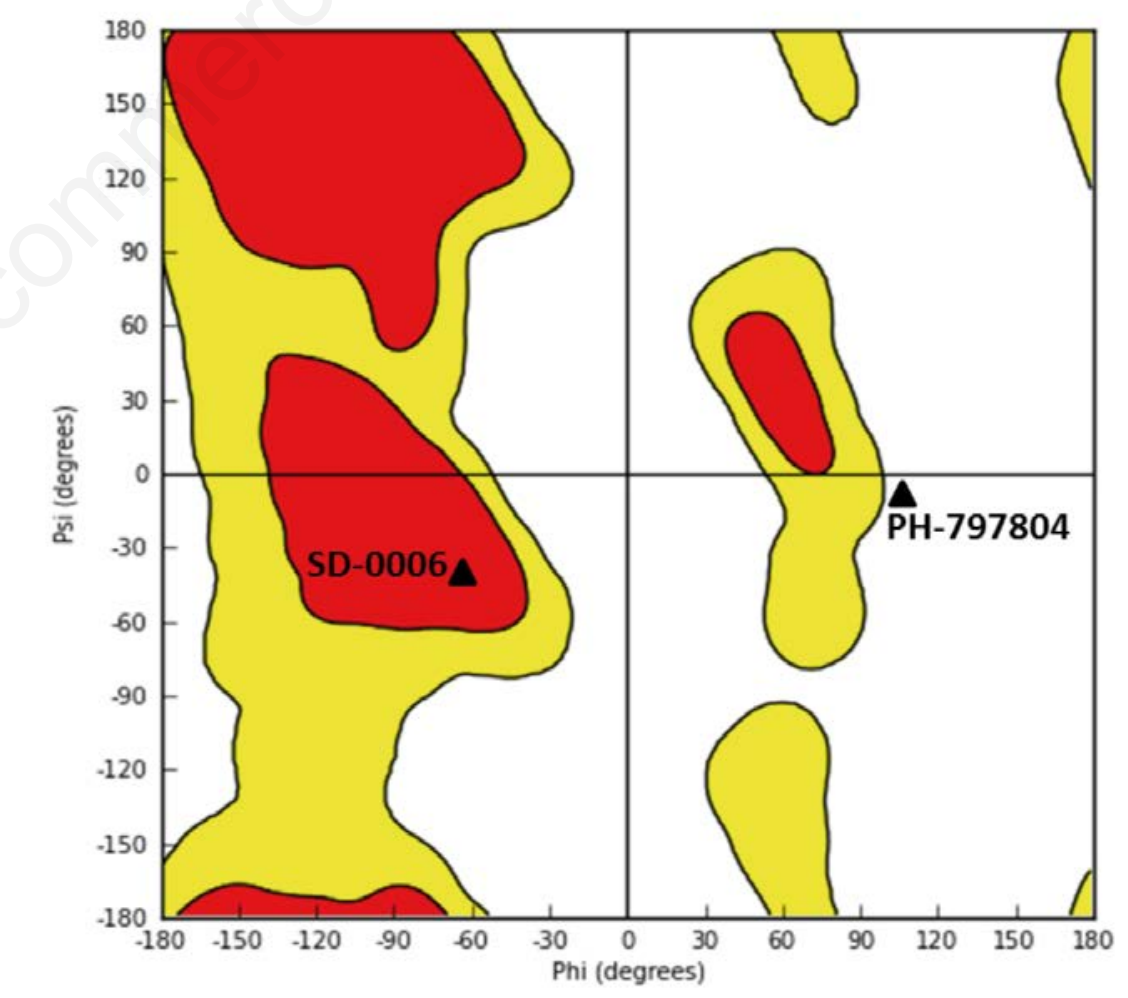

Figure 3. Ramachandran diagram of $\mathrm{p} 38 \alpha$ kinase Gly110. Labeled by triangles are the measured $\psi$ and $\varphi$ dihedrals of crystal structures of the binary complexes of SD-0006 and PH-797804 (PDB codes 3HL7 and 3HLL). The areas filled by red and yellow contours delineate favored and disfavored but allowed regions respectively. The unfilled region is disallowed. 
with biochemical measurements. Treatment of rats with PH-797804 resulted in dose-dependent inhibition of LPS-induced TNF- $\alpha$ production, yielding an $\mathrm{ED}_{80}$ value of $0.3 \mathrm{mg} / \mathrm{kg} .{ }^{85} \mathrm{In}$ a chronic model PH-797804 was highly effective in attenuating strep cell well (SCW)-induced inflammation, yielding dose-dependent inhibition of paw swelling $\left(\mathrm{ED}_{50}: 0.186 \mathrm{mg} / \mathrm{kg}\right)$. In a double-blind, placebo-controlled, single-dose study in healthy human subjects PH-797804 was proven to be safe and well tolerated, supported by its high level of potency, selectivity and biochemical efficiency. In moderate-to-severe COPD patients' efficacy was achieved in several proof-of-concept studies.

\section{Conclusions}

A number of competitive p38 kinase inhibitors have been reported to show early signs of anti-inflammatory efficacy in Phase Ila studies of rheumatoid arthritis over the years. For the treatment of chronic diseases small molecule kinase inhibitors have to be highly specificity in order to avoid unwanted effects caused by off-target inhibition. This is a high hurdle considering that the human kinome contains over 500 protein kinases sharing varying degrees of sequence homology. Structural insights into the unique p38 binding mechanism have guided discovery of several highly selective inhibitors.

Inflammation acts along complex and overlapping pathways. Although p38 $\alpha$ was originally proposed to carry predominantly pro-inflammatory functions, increasing evidence suggested that it also has crucial roles in tuning down inflammatory responses in specific cell types. It remains unknown whether compensatory up-regulation of redundant or parallel pathways or auto-activation of the p38 signaling system may attenuate potential benefit of the investigational anti-inflammatory therapeutics. ${ }^{86}$ Most of the clinical p38 programs have been terminated due to the lack of prolonged efficacy during the trial period of several months. They showed early suppression of CRP that was not sustained and often reversed by $2-4$ weeks into the study, hence failed to demonstrate statistically significant efficacy. The results suggest that other inflammatory pathways may have been up-regulated in response to prolonged p38 blockade. The modest clinical efficacy plus the transient suppression of biomarkers of inflammation observed in multiple studies suggest that p38 MAPK inhibition may not provide meaningful, sustained suppression of the chronic inflammation. It remains debatable whether it is preferable to combine inhibition of p38 with other targets in parallel inflammatory signaling pathways to achieve the desired efficacy in chronic inflammatory diseases. A mechanistic understanding of the clinical phenomenon would help direct efforts toward next generation of potentially promising therapies.

\section{References}

1. Cotsapas C, Hafler DA. Immune-mediated disease genetics: the shared basis of pathogenesis. Trends Immunol 2013;34: 22-6.

2. Bresnihan B. Pathogenesis of joint damage in rheumatoid arthritis. J Rheumatol 1999;26:717-9.

3. Rose NR, Bona C. Defining criteria for autoimmune diseases (Witebsky's postulates revisited). Immunol Today 1993;14: 426-30.

4. Gan WQ, Man SF, Senthilselvan A, Sin DD. Association between chronic obstructive pulmonary disease and systemic inflammation: a systematic review and a metaanalysis. Thorax 2004;59:574-80.

5. Agusti A, MacNee W, Donaldson K, Cosio M. Hypothesis: does COPD have an autoimmune component? Thorax 2003;58: 832-4.

6. Barnes PJ. Chronic obstructive pulmonary disease. N Engl J Med 2000;343:269-80.

7. Okamoto H, Hoshi D, Kiire A, et al. Molecular targets of rheumatoid arthritis. Inflamm Allergy Drug Targets 2008;7:53-66.

8. Kievit W, Fransen J, Oerlemans A, et al. The efficacy of anti-TNF in rheumatoid arthritis, a comparison between randomised controlled trials and clinical practice. Ann Rheum Dis 2007;66:1473-8.

9. St Clair EW, van der Heijde DM, Smolen JS, et al. Combination of infliximab and methotrexate therapy for early rheumatoid arthritis: a randomized, controlled trial. Arthritis Rheum 2004;50:3432-43.

10. Weinblatt ME, Keystone EC, Furst DE, et al. Long term efficacy and safety of adalimumab plus methotrexate in patients with rheumatoid arthritis: ARMADA 4 year extended study. Ann Rheum Dis 2006;65: 753-9.

11. Genovese MC, Cohen S, Moreland L, et al. Combination therapy with etanercept and anakinra in the treatment of patients with rheumatoid arthritis who have been treated unsuccessfully with methotrexate. Arthritis Rheum 2004;50:1412-9.

12. Maini RN, Taylor PC, Szechinski J, et al. Double-blind randomized controlled clinical trial of the interleukin-6 receptor antagonist, tocilizumab, in European patients with rheumatoid arthritis who had an incomplete response to methotrexate. Arthritis Rheum 2006;54:2817-29.

13. Choy EHS, Panayi GS. Cytokine pathways and joint inflammation in rheumatoid arthritis. N Engl J Med 2001;344:907-16.

14. Waetzig GH, Seegert D, Rosenstiel P, et al. p38 mitogen-activated protein kinase is activated and linked to TNF-alpha signaling in inflammatory bowel disease. $\mathrm{J}$ Immunol 2002;168:5342-51.

15. Raingeaud J, Gupta S, Rogers JS, et al. Pro-inflammatory cytokines and environmental stress cause p38 mitogen-activated protein kinase activation by dual phosphorylation on tyrosine and threonine. J Biol Chem 1995;270:7420-6.

16. Adams JL, Badger AM, Kumar S, Lee JC. p38 MAP kinase: molecular target for the inhibition of pro-inflammatory cytokines. Prog Med Chem 2001;38:1-60.

17. Schieven GL. The biology of p38 kinase: a central role in inflammation. Curr Top Med Chem 2005;5:921-8.

18. Arthur JS, Ley SC. Mitogen-activated protein kinases in innate immunity. Nat Rev Immunol 2013;13:679-92.

19. Kumar S, Boehm J, Lee JC. p38 MAP kinases: key signalling molecules as therapeutic targets for inflammatory diseases. Nat Rev Drug Discov 2003;2:717-26.

20. Saklatvala J. The p38 MAP kinase pathway as a therapeutic target in inflammatory disease. Curr Opin Pharmacol 2004;4:372-7.

21. Peifer C, Wagner G, Laufer S. New approaches to the treatment of inflammatory disorders small molecule inhibitors of p38 MAP kinase. Curr Top Med Chem 2006;6:113-49.

22. Pettus LH, Wurz RP. Small molecule p38 MAP kinase inhibitors for the treatment of inflammatory diseases: novel structures and developments during 2006-2008. Curr Top Med Chem 2008;8:1452-67.

23. Goldstein DM, Kuglstatter A, Lou Y, Soth MJ. Selective p38alpha inhibitors clinically evaluated for the treatment of chronic inflammatory disorders. J Med Chem 2010;53:2345-53.

24. Kumar S, McDonnell PC, Gum RJ, et al. Novel homologues of CSBP/p38 MAP kinase: activation, substrate specificity and sensitivity to inhibition by pyridinyl imidazoles. Biochem Biophys Res Commun 1997;235:533-8.

25. Chanteux H, Guisset AC, Pilette C, Sibille Y. LPS induces IL-10 production by human alveolar macrophages via MAPKinases- and Spl-dependent mechanisms. Respiratory Res 2007;8:71.

26. Wadgaonkar R, Pierce JW, Somnay K, et al. Regulation of c-Jun N-terminal kinase and p38 kinase pathways in endothelial cells. Am J Respir Cell Mol Biol 2004;31:423-31.

27. Shin MS, Shinghirunnusorn P, Sugishima $\mathrm{Y}$, et al. Cross interference with TNFalpha-induced TAK1 activation via EGFRmediated p38 phosphorylation of TAK1binding protein 1. Biochim Biophys Acta 2009;1793:1156-64.

28. Fiebich BL, Mueksch B, Boehringer M, 
Hull M. Interleukin-1beta induces cyclooxygenase-2 and prostaglandin E(2) synthesis in human neuroblastoma cells: involvement of p38 mitogen-activated protein kinase and nuclear factor-kappaB. J Neurochem 2000;75:2020-8.

29. Duffy JP, Harrington EM, Salituro FG, et al. The Discovery of VX-745: A Novel and Selective p38alpha Kinase Inhibitor. ACS Med Chem Lett 2011;2:758-63.

30. Norman P. Advances in anti-arthritic agents. SMI's Thrid Annual Conference. IDrugs 2002;2002:530-8.

31. Ding C. Drug evaluation: VX-702, a MAP kinase inhibitor for rheumatoid arthritis and acute coronary syndrome. Curr Opin Investig Drugs 2006;7:1020-5.

32. Damjanov N, Kauffman RS, Spencer-Green GT. Efficacy, pharmacodynamics, and safety of VX-702, a novel p38 MAPK inhibitor, in rheumatoid arthritis: results of two randomized, double-blind, placebo-controlled clinical studies. Arthritis Rheum 2009;60: 1232-41.

33. Nikas SN, Drosos AA. SCIO-469 Scios Inc. Curr Opin Investig Drugs 2005;5:1205-12.

34. Genovese MC, Cohen SB, Wofsy D, et al., eds. A randomized, double-blind, placebocontrolled phase 2 study of an oral p38a MAPK inhibitor, SCIO-469, in patients with active rheumatoid arthritis (abstract). Proc. American College of Rheumatology 2008 Annual Meeting; 2008 0ct 24-29; San Francisco, CA: American College of Rheumatology, Atlanta, GA.

35. Genovese MC, Cohen SB, Wofsy D, et al. A 24-week, randomized, double-blind, placebo-controlled, parallel group study of the efficacy of oral SCI0-469, a p38 mitogenactivated protein kinase inhibitor, in patients with active rheumatoid arthritis. J Rheumatol 2011;38:846-54.

36. Sokol L, Cripe L, Kantarjian H, et al. Randomized, dose-escalation study of the p38alpha MAPK inhibitor SCIO-469 in patients with myelodysplastic syndrome. Leukemia 2013;27:977-80.

37. Tong SE, Deniels SE, Montano T, et al. Scio469, a novel p38a MAPK inhibitor, provides efficacy in acute post-surgical dental pain. Clin Pharmacol Ther 2004;75:3.

38. Murali Dhar TG, Wrobleski ST, Lin S, et al. Synthesis and SAR of p38alpha MAP kinase inhibitors based on heterobicyclic scaffolds. Bioorg Med Chem Lett 2007;17:5019-24.

39. Laufer S, Lehmann F. Investigations of SCI0-469-like compounds for the inhibition of p38 MAP kinase. Bioorg Med Chem Lett 2009;19:1461-4.

40. Pargellis C, Tong L, Churchill L, et al. Inhibition of p38 MAP kinase by utilizing a novel allosteric binding site. Nat Struct Biol 2002;9:268-72.

41. Sullivan JE, Holdgate GA, Campbell D, et al. Prevention of MKK6-Dependent Activation by Binding to p38alpha MAP Kinase. Biochemistry 2005;44:16475-90.

42. Kuma Y, Sabio G, Bain J, et al. BIRB796 inhibits all p38 MAPK isoforms in vitro and in vivo. J Biol Chem 2005;280:19472-9.

43. Graneto MJ, Kurumbail RG, Vazquez ML, et al. Synthesis, crystal structure, and activity of pyrazole-based inhibitors of $\mathrm{p} 38$ kinase. J Med Chem 2007;50:5712-9.

44. Walker JK, Selness SR, Devraj RV, et al. Identification of SD-0006, a potent diaryl pyrazole inhibitor of p38 MAP kinase. Bioorg Med Chem Lett 2010;20:2634-8.

45. Burnette BL, Selness S, Devraj R, et al. SD0006: a potent, selective and orally available inhibitor of p38 kinase. Pharmacology 2009;84:42-60.

46. Hill RJ, Dabbagh K, Phippard D, et al. Pamapimod, a novel p38 mitogen-activated protein kinase inhibitor: preclinical analysis of efficacy and selectivity. J Pharmacol Exp Ther 2008;327:610-9.

47. Cohen SB, Cheng TT, Chindalore V, et al. Evaluation of the efficacy and safety of pamapimod, a p38 MAP kinase inhibitor, in a double-blind, methotrexate-controlled study of patients with active rheumatoid arthritis. Arthritis Rheum 2009;60:335-44.

48. Genovese MC. Inhibition of p38: has the fat lady sung? Arthritis Rheum 2009;60: 317-20.

49. Singh D, Smyth L, Borrill Z, et al. A randomized, placebo-controlled study of the effects of the p38 MAPK inhibitor SB681323 on blood biomarkers of inflammation in COPD patients. J Clin Pharmacol 2010;50:94-100.

50. Anand P, Shenoy R, Palmer JE, et al. Clinical trial of the p38 MAP kinase inhibitor dilmapimod in neuropathic pain following nerve injury. Eur J Pain 2011;15:1040-8.

51. Aston NM, Bamborough P, Buckton JB, et al. p38alpha mitogen-activated protein kinase inhibitors: optimization of a series of biphenylamides to give a molecule suitable for clinical progression. J Med Chem 2009;52:6257-69.

52. Marks-Konczalik J, Costa M, Robertson J, et al. A post-hoc subgroup analysis of data from a six month clinical trial comparing the efficacy and safety of losmapimod in moderate-severe COPD patients with $<=2 \%$ and $>2 \%$ blood eosinophils. Respir Med 2015;109:860-9.

53. Ostenfeld T, Krishen A, Lai RY, et al. A randomized, placebo-controlled trial of the analgesic efficacy and safety of the p38 MAP kinase inhibitor, losmapimod, in patients with neuropathic pain from lumbosacral radiculopathy. Clin J Pain 2015; 31:283-93.

54. Cheriyan J, Webb AJ, Sarov-Blat L, et al. Inhibition of p38 mitogen-activated pro- tein kinase improves nitric oxide-mediated vasodilatation and reduces inflammation in hypercholesterolemia. Circulation 2011;123:515-23.

55. Elkhawad M, Rudd JH, Sarov-Blat L, et al. Effects of p38 mitogen-activated protein kinase inhibition on vascular and systemic inflammation in patients with atherosclerosis. JACC Cardiovasc Imaging 2012;5: 911-22.

56. Newby LK, Marber MS, Melloni C, et al. Losmapimod, a novel p38 mitogen-activated protein kinase inhibitor, in non-ST-segment elevation myocardial infarction: a randomised phase 2 trial. Lancet 2014;384: 1187-95.

57. Novartis A, inventor. Use of a pyrazole derivative in the treatment of acute exacerbations of chronic obstructive pulmonary disease. US2013.

58. Novartis A, inventor. 5-membered heterocycle-based p38 kinase inhibitors. US2012.

59. Wadsworth SA, Cavender DE, Beers SA, et al. RWJ 67657, a potent, orally active inhibitor of p38 mitogen-activated protein kinase. J Pharmacol Exp Ther 1999;291: 680-7.

60. Parasrampuria DA, de Boer P, DesaiKrieger D, et al. Single-dose pharmacokinetics and pharmacodynamics of RWJ 67657, a specific p38 mitogen-activated protein kinase inhibitor: a first-in-human study. J Clin Pharmacol 2003;43:406-13.

61. Fijen JW, Zijlstra JG, De Boer P, et al. Suppression of the clinical and cytokine response to endotoxin by RWJ-67657, a p38 mitogen-activated protein-kinase inhibitor, in healthy human volunteers. Clin Exp Immunol 2001;124:16-20.

62. Antoon JW, Bratton MR, Guillot LM, et al. Pharmacology and anti-tumor activity of RWJ67657, a novel inhibitor of p38 mitogen activated protein kinase. Am J Cancer Res 2012;2:446-58.

63. Xing L, Shieh HS, Selness SR, et al. Structural bioinformatics-based prediction of exceptional selectivity of p38 MAP kinase inhibitor PH-797804. Biochem 2009;48:6402-11.

64. Selness SR, Devraj RV, Monahan JB, et al. Discovery of $\mathrm{N}$-substituted pyridinones as potent and selective inhibitors of p38 kinase. Bioorg Med Chem Lett 2009;19: 5851-6.

65. Selness SR, Devraj RV, Devadas B, et al. Discovery of PH-797804, a highly selective and potent inhibitor of p38 MAP kinase. Bioorg Med Chem Lett 2011;21:4066-71.

66. Selness SR, Boehm TL, Walker JK, et al. Design, synthesis and activity of a potent, selective series of $\mathrm{N}$-aryl pyridinone inhibitors of p38 kinase. Bioorg Med Chem Lett 2011;21:4059-65.

67. Jiang JK, Shen M, Thomas CJ, Boxer MB. 
Chiral kinase inhibitors. Curr Top Med Chem 2011;11:800-9.

68. MacNee W, Allan RJ, Jones I, et al. Efficacy and safety of the oral p38 inhibitor PH797804 in chronic obstructive pulmonary disease: a randomised clinical trial. Thorax 2013;68:738-45.

69. Fogel R, Shields K, Christensen J, et al, eds. A phase II, randomised, placebo controlled trial of 12 weeks treatment with an oral p38 inhibitor in patients with COPD on a background of ICS/LABA. European Respiratory Society Annual Congress; 2013 September 7-11, 2013; Barcelona, Spain.

70. Campbell RM, Anderson BD, Brooks NA, et al. Characterization of LY2228820 dimesylate, a potent and selective inhibitor of p38 MAPK with antitumor activity. Mol Cancer Ther 2014;13:364-74.

71. Array Homepage. Available from: http:// investor.arraybiopharma.com/phoenix.zht $\mathrm{ml}$ ? $\mathrm{c}=123810 \& \mathrm{p}=$ irol-newsArticle \&ID $=$ 1305781\&highlight=Accessed: Oct 16, 2015.

72. Amgen Homepage. Available from: http://wwwext.amgen.com/media/media_p r_detail.jsp?year $=2003 \&$ releaseID $=51478$ 5 Accessed: Oct 16, 2015.

73. BMS Homepage. Available from: http://ctr. bms.com/OneBmsCtd/InitTrialDetailActio n.do?pnum=IM119-015 Accessed: 0ct 16, 2015.
74. Wang Z, Harkins PC, Ulevitch RJ, et al. The structure of mitogen-activated protein kinase p38 at 2.1-A resolution. Proc Natl Acad Sci U S A 1997;94:2327-32.

75. Wilson KP, Fitzgibbon MJ, Caron PR, et al. Crystal structure of p38 mitogen-activated protein kinase. J Biol Chem 1996;271: 27696-700.

76. Shewchuk L, Hassell A, Wisely B, et al. Binding mode of the 4-anilinoquinazoline class of protein kinase inhibitor: X-ray crystallographic studies of 4-anilinoquinazolines bound to cyclin-dependent kinase 2 and p38 kinase. J Med Chem 2000;43: 133-8.

77. Wang Z, Canagarajah BJ, Boehm JC, et al. Structural basis of inhibitor selectivity in MAP kinases. Structure 1998;6:1117-28.

78. Tong L, Pav S, White DM, et al. A highly specific inhibitor of human p38 MAP kinase binds in the ATP pocket. Nat Struct Biol 1997;4:311-6.

79. Stelmach JE, Liu L, Patel SB, et al. Design and synthesis of potent, orally bioavailable dihydroquinazolinone inhibitors of p38 MAP kinase. Bioorg Med Chem Lett 2003; 13:277-80.

80. Trejo A, Arzeno H, Browner M, et al. Design and synthesis of 4-azaindoles as inhibitors of p38 MAP kinase. J Med Chem 2003;46:4702-13.
81. Goldstein DM, Alfredson T, Bertrand J, et al. Discovery of S-[5-amino-1-(4-fluorophenyl)1H-pyrazol-4-yl]-[3-(2,3-dihydroxypropoxy) ph enyl]methanone (R03201195), an orally bioavailable and highly selective inhibitor of p38 MAP kinase. J Med Chem 2006;49: 1562-75.

82. Gill AL, Frederickson M, Cleasby A, et al. Identification of novel p38alpha MAP kinase inhibitors using fragment-based lead generation. J Med Chem 2005;48:414-26.

83. Huse M, Kuriyan J. The conformational plasticity of protein kinases. Cell 2002;109: 275-82.

84. Jacobs MD, Caron PR, Hare BJ. Classifying protein kinase structures guides use of ligand-selectivity profiles to predict inactive conformations: structure of lck/imatinib complex. Proteins 2008;70:1451-60.

85. Hope HR, Anderson GD, Burnette BL, et al. Anti-inflammatory properties of a novel Nphenyl pyridinone inhibitor of p38 mitogen-activated protein kinase: preclinicalto-clinical translation. J Pharmacol Exp Ther 2009;331:882-95.

86. Cohen P. Targeting protein kinases for the development of anti-inflammatory drugs. Curr Opin Cell Biol 2009;21:317-24. 